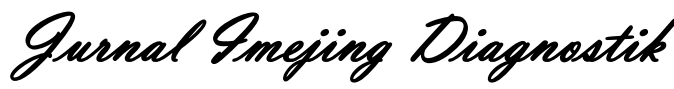

e-ISSN 2621-7457, p-ISSN 2356-301X http://ejournal.poltekkessmg.ac.id/ojs/index.php/jimed/index

\title{
Pemeriksaan Mri Pelvis Dengan Menggunakan Ultrasonic Gel Pada Kasus Endometriosis Di Instalasi Radiologi Mayapada Hospital Jakarta Selatan
}

\author{
Legif Leboka Sepra $^{1)}$, Siti Masrochah ${ }^{1)}$, Bagus Abimanyu ${ }^{1)}$ \\ 1) Jurusan Teknik Radiodiagnostik dan radioterapi Poltekkes Kemenkes Semarang, Indonesia \\ e-mail : legif24@gmail.com
}

Received: Mey $31^{\text {th }}, 2019$; Revised: July 01 ${ }^{\text {st }}, 2019$; Accepted: July 09 ${ }^{\text {th }}, 2019$

\begin{abstract}
Introduction: Pelvic MRI examination in endometriosis cases does not theoretically use an ultrasonic gel that is inserted into the vagina and rectum, but also for sequences used without using the T1 sequence. Sagittal cut fat suppression. Radiology Installation of Mayapada Hospital, South Jakarta for Pelvic MRI examination with Endometriosis cases using Gel and T1_SPIR sequences from these differences, the aim of knowing the role of gel and sequencing of T1_SPIR Sagittal pieces.

Method: This type of research is qualitative research with a case study approach. The method of data collection is done by observation, in-depth interviews with radiographers, radiology specialists, doctors, and documentation. Data analysis is done by an interactive model, then the data is presented in the form of the narrative text so that conclusions can be drawn.

Results: The results showed that Pelvic MRI examination using Ultrasonic Gel in Endometriosis Cases used ultrasonic gel in the 50cc and 150cc vaginal organs, the sequences used T2W_TSE, T2W_SPIR, T1_SPIR, T1W, T2_FFE on Sagittal snippets, T2W_TSE, T2W_SPAIR, T1W_SPIR on coronal chunks, T1W_TSE, T1W_TSE_SPIR, T2W_TSE on axial chunks and DWI_3b_RT SENSE on axial chunks and SSh_URETER. The reason for using ultrasonic gel on MRI examination in the Pelvis is to see a clear difference between normal tissue and pathological tissue, expressly demarcate organ boundaries, play a role in widening the vaginal cavity and rectum. The reason for adding the sagittal cut T1_SPIR sequence in the case of Endometriosis to show lesions suspected of blood or other intensity and to ensure bleeding.
\end{abstract}

Keyword : MRI Pelvis; Ultrasonic Gel; Endometriosis; T1_SPIR_Sagital.

\section{Pendahuluan}

Magnetic Resonance Imaging (MRI) adalah suatu alat kedokteran di bidang pemeriksaan diagnostik radiologi, yang menghasilkan rekaman gambar potongan penampang tubuh / organ manusia dengan menggunakan medan magnet. Beberapa faktor kelebihan yang dimilikinya, terutama kemampuan membuat potongan koronal, sagital, axial dan oblik tanpa banyak memanipulasi posisi tubuh pasien sehingga sangat sesuai untuk diagnostik jaringan lunak (Notosiswoyo, 2004).

Pelvis merupakan struktur tulang yang terdapat di dasar tulang belakang. Pelvis satu kesatuan dengan sambungan hip joint untuk masing-masing kaki. Pelvis juga berfungsi melindungi organ reproduksi dan pencernaan yang terdapat pada bagian bawah dari tubuh, dan banyak pembuluh darah dan otot saraf besar yang melewatinya dari tubuh bagian atas ke bagian kaki (Suprijanto et al, 2009). Indikasi pemeriksaan MRI Pelvis yaitu kelainan kongenital pada urogenitalia, kelainan pada sistem reproduksi, termasuk diagnosis dari endometriosis, tumor jinak pada rahim dan Infertilitas (Westbrook, 2014).

Endometriosis merupakan kondisi medis pada wanita yang ditandai dengan tumbuhnya sel-sel endometrium di luar kavum uteri. Sel-sel endometrium yang melapisi kavum uteri sangat dipengaruhi hormon wanita (Hormon estrogen). Dalam keadaan normal, sel-sel endometrium kavum uteri akan menebal selama siklus menstruasi berlangsung agar nantinya siap menerima hasil pembuahan sel telur oleh sperma (Suparman,2012).

Pada pemeriksaan MRI Pelvis tidak ada persiapan khusus sebelum pemeriksaan, tetapi pasien diminta untuk tahan kencing sebelum pemeriksaan (kandung kemih harus penuh), tetapi pasien diberi penjelasan tentang berbagai posisi dan prosedur pemeriksaan yang akan dilakukan (Westbrook, 2014).

Menurut Moeller (2003) pemilahan sekuens pada pemeriksaan MRI Pelvis rutin adalah T2 FSE (Fast Spin Echo), T2 fat saturation, T1 FSE dan T1 fat saturation pada potongan axial. Selanjutnya pada potongan coronal sekuens yang digunakan 
adalah T2 TIRM (Turbo Inversion Recovery Magnitude) / STIR (Short Tau Inversion Recovery) atau T2 FSE dan T2 fat saturation. Sedangkan untuk potongan sagital menggunakan T2 FSE. Pembobotan sekuens setelah pemberian media kontras adalah axial $\mathrm{T} 1$ dan Coronal $\mathrm{T} 1$ jika diperlukan.

Berdasarkan pengamatan penulis di Instalasi Radiologi Mayapada Hospital Jakarta Selatan, pasien dengan kasus endometriosis ditemukan ratarata sebulan antara 1-3 pasien dengan menggunakan sekuen T2W_TSE(Turbo Spin Echo), T2W_SPIR (Spectral Pre-Saturation With Inversion Recovery), T1_SPIR, T1W, T2_FFE (Fast Field Echo) pada irisan sagital, T1W_TSE, T1W_TSE_SPIR, T2W_TSE, DWI_3b_RT SENSE pada irisan axial dan T2W_TSE, T2W_SPAIR, T1W_SPIR pada irisan coronal.

Di Instalasi Radiologi Mayapada Hospital Jakarta Selatan untuk pemeriksaan MRI pelvis sebelum pemeriksaan pasien diberi ultrasonic gel di vagina dan rectum dan disini peneliti juga menemukan adanya penambahan sekuens yaitu pembobotan T1 _SPIR pada potongan sagital. Oleh karena itu, perlu diteliti peranan ultrasonic gel pada pemeriksaan MRI Pelvis dan peranan pembobotan sekuens T1_SPIR potongan sagital pada kasus endometriosis.

\section{Metode}

Jenis penelitian ini adalah penelitian kualitatif dengan pendekatan studi kasus. Subyek penelitian terdiri dari satu orang pasien MRI Pelvis dengan kasus endometriosis, tiga orang radiografer dengan kriteria terlibat langsung dalam menangani pemeriksaan MRI Pelvis di Instalasi Radiologi Mayapada Hospital Jakarta Selatan dan memiliki pengalaman yang cukup lama dalam bidang MRI, dua orang radiolog yang membaca expertise serta satu orang dokter pengirim pasien dengan kasus endometriosis.

Instrumen penelitian terdiri dari pedoman observasi, pedoman wawancara, recorder dan kamera digital. Metode pengumpulan data dilakukan dengan cara observasi, wawancara mendalam dengan radiografer, dokter spesialis radiologi dan dokter pengirim serta dokumentasi. Analisa data dilakukan dengan interactive model, kemudian data disajikan dalam bentuk teks naratif sehingga dapat ditarik kesimpulan.

\section{Hasil dan Pembahasan}

Prosedur Pemeriksaan MRI Pelvis dengan Menggunakan Ultrasonic Gel pada Kasus

\section{Endometriosis di Instalasi Radiologi Mayapada Hospital Jakarta Selatan}

Penelitian ini menggunakan pasien wanita dengan klinis endometriosis, umur 32 tahun, mengeluhkan sakit yang berlebihan di daerah perut dan mengeluarkan darah yang cukup banyak saat menstruasi serta masih belum mempunyai keturunan. Persiapan alat dan bahan dapat dilihat pada tabel 1.

Tabel 1. Persiapan alat dan bahan

\begin{tabular}{cc}
\hline Persiapan Alat & Persiapan Bahan \\
\hline Pesawat MRI & Ultrasonic Gel \\
Body Coil & Catheter Tip 150 cc \\
Selimut & Buscopan \\
Fixing Belt & Spuit 5 cc \\
Headset & Handscoon \\
Printer & Mikropore \\
\hline
\end{tabular}

Persiapan pasien pada pemeriksaan MRI Pelvis dengan menggunakan ultrasonic gel pada kasus endometriosis di Instalasi Radiologi Mayapada Hospital Jakarta Selatan tidak memerlukan persiapan khusus cuma pasien di instruksikan tahan kencing. Untuk kasus endometriosis tidak diperlukan pemeriksaan dengan menggunakan kontras kecuali curiga adanya kanker atau tumor atau infeksi lainnya.

Persiapan alat dan bahan pada pemeriksaan MRI Pelvis dengan menggunakan ultrasonic gel pada kasus endometriosis di Instalasi Radiologi Mayapada Hospital Jakarta Selatan adalah sebagai berikut: Pesawat MRI, body coil, selimut, bantal kepala, fixing belt, headset yang dilengkapi dengan music, printer serta komputer dan work station. Dalam hal ini untuk persiapan alat dan bahan pada pemeriksaan MRI Pelvis dengan menggunakan ultrasonic gel pada kasus endometriosis di instalasi radiologi mayapada hospital jakarta selatan sudah sesuai dengan teori menurut (Westbrook, 2014). Perbedaannya terdapat pada persiapan alat dan bahan untuk pemasukkan gel yaitu ultrasonic gel, catheher tip $50 \mathrm{cc}$, buscopan, spuit $5 \mathrm{cc}$, handscon dan mikropor.

Menurut pendapat penulis, persiapan alat dan bahan yang dilakukan pada pemeriksaan MRI Pelvis dengan menggunakan ultrasonic gel pada kasus endometriosis di Instalasi Radiologi Mayapada Hospital Jakarta Selatan sudah cukup baik, namun perlu adanya tempat atau ruang persiapan khusus agar memudahkan petugas dalam menjangkau alat dan bahan yang diperlukan pada saat tindakan. Ruang persiapan alat dan bahan untuk alat kesehatan masih menyatu dengan ruang persiapan rontgen konvensional sehingga akan 
bepengaruh terhadap lamanya waktu pemeriksaan dan menyulitkan pekerjaan radiografer melakukan pemeriksaan.

Secara umum persiapan pasien pada pemeriksaan MRI Pelvis dengan menggunakan Ultrasonic Gel pada kasus Endometriosis di Instalasi Radiologi Mayapada Hospital Jakarta Selatan sudah sesuai dengan teori menurut (Moeller,2003). Pada pemeriksaan ini tidak ada persiapan khusus lainnya cuma pasien tahan kencing. Sebaiknya instruksi-instruksi yang menyangkut pemeriksaan harus dijelaskan tidak hanya kepada pasien tetapi juga kepada keluarga pasien yang ikut menemani pasien. Keluarga dapat membantu meyakinkan atau menenangkan pasien agar tidak bergerak selama pemeriksaan, bila perlu salah satu keluarga dapat ikut menunggu pasien di dalam ruang MRI selama pemeriksaan berlangsung sehingga pasien akan merasa nyaman. Dengan demikian radiografer dapat mengerjakan pemeriksaan dengan lancar.

Posisi pasien pada pemeriksaan MRI Pelvis dengan menggunakan ultrasonic gel pada kasus Endometriosis di Instalasi Radiologi Mayapada Hospital Jakarta Selatan yaitu pasien diatur tidur terlentang. Kaki dekat gantry (feet first), posisi pasien diatur sehingga Mid Sagital Plane (MSP) tepat dan sejajar dengan lampu indikator longitudinal. Tangan diatas kepala supaya tidak menganggu obyek yang akan diperiksa atau timbulnya artefak. Koil body dipasang di atas perut pasien. Perhatikan posisi koil body terhadap pasien, koil body diatur dengan central point dipertengahan pelvis. Fixing belt dipasang, tetapi diikat longgar agar pasien merasa nyaman, tetapi koil tidak mudak bergeser. Pasangkan headset pada kedua telinga. Emergency buzzer diberikan untuk dipegang pasien, yang bisa ditekan tombolnya jika pasien merasa tidak nyaman saat pemeriksaan berlangsung. Agar tidak kedinginan dan untuk kenyamanan pasien diberi selimut. Secara umum hal ini sudah sesuai dengan positioning pemeriksaan MRI Pelvis menurut (Westbrook,2014).

Menurut penulis, pengaturan posisi pasien diusahakan senyaman mungkin, dengan tidur supine diatas meja pemeriksaan. Hal-hal yang perlu diperhatikan adalah selama berlangsungnya tindakan adalah pasien tidak boleh bergerak sehingga tidak terjadi artefact, kemudian posisi pasien diatur sehingga Mid Sagital Plane (MSP) tepat dan sejajar dengan lampu indikator longitudinal. Beri pasien softbag agar pasien merasa lebih nyaman karena waktu pemeriksaan MRI pelvis sangat lama.
Setelah dilakukan pengaturan posisi pasien maka selanjutnya melengkapi registrasi pasien meliputi : nama, umur, jenis kelamin, no. Registrasi tindakan, berat badan, diagnosa, dokter pengirim dan radiologist serta jenis pemeriksaan yang dilakukan.

Scanning pemeriksaan MRI Pelvis dengan menggunakan ultrasonic gel pada kasus endometriosis di Instalasi Radiologi Mayapada Hospital Jakarta Selatan diawali dengan pembuatan survey. Pada survey dibuat dalam bentuk survey 3 plane sehingga dihasilkan survey dari irisan axial, coronal, dan sagital. Selanjutnya sekuens pemeriksaan yang dilakukan pada pemeriksaan meliputi: T2W_TSE, T2W_SPIR, T1_SPIR, T1W, T2_FFE pada potongan sagital, T1W_TSE, T1W_TSE_SPIR, T2W_TSE pada potongan axial, T2W_TSE, T2W_SPAIR, T1W_SPIR pada potongan coronal. Selain itu dilakukan penambahan sekuen DWI_3b_RT SENSE pada potongan axial untuk melihat curiga adanya tumor atau kanker dan dan SSh_URETER atau single shot ureter. Sedangkan Menurut Moeller (2003) pemilahan sekuens pada pemeriksaan MRI Pelvis rutin adalah T2 FSE (Fast Spin Echo), T2 fat saturation, T1 FSE (Fast Spin Echo), dan T1 fat saturation pada potongan axial. Selanjutnya pada potongan coronal sekuens yang digunakan adalah T2 TIRM/STIR atau T2 FSE (Fast Spin Echo) dan T2 fat saturation. Sedangkan untuk potongan sagital menggunakan T2 FSE (Fast Spin Echo). Pembobotan sekuens setelah pemberian media kontras adalah axial $\mathrm{T} 1$ dan Coronal T1 jika diperlukan. Fungsi masingmasing sekuens dijelaskan pada tabel 2.

Menurut responden 4 Radiologist Mayapada Hospital Jakarta Selatan sekuens pada pemeriksaan MRI Pelvis pada kasus endometriosis semuanya penting untuk menegakkan diagnosa tetapi untuk sekuens tambahan single shot ureter tidak begitu optimal untuk pemeriksaan. Penulis berpendapat lebih baik menggunakan parameter yang dinilai lebih informatif saja . Dengan penggunaan semua sekuens lengkap tentu saja akan mempengaruhi scan time (lamanya waktu pemeriksaan). Semakin lama waktu pemeriksaan akan berpengaruh terhadap kenyamanan pasien yang sedang berada didalam bore magnet. Jika pasien sudah merasa tidak nyaman maka kemungkinan besar pasien akan bergerak. Hal tersebut akan mempengaruhi hasil gambaran yang menjadi kabur sehingga waktu pengambilan gambar harus diulang kembali. Selain itu suara yang bising yang diterima pasien juga akan menjadi bertambah yang menyebabkan pasien semakin merasa tidak nyaman. 
Secara teknis dalam proses pengambilan gambar, TR, TE, FOV, slice thickness, slice gap sangat mempengaruhi hasil gambaran MRI. Semua yang digunakan disini mulai dari proses pengambilan gambar, TR, TE, FOV, slice thickness, slice gap secara umum sudah sesuai dengan teori menurut Moeller (2003). Tetapi menurut penulis untuk penggunaan slice gap jangan terlalu kecil karena penggunaan slice gap yang semakin kecil akan memperpanjang waktu pemeriksaan dan menaikkan jumlah slices (banyaknya irisan), maka akan berpengaruh terhadap scan time atau lamanya waktu pemeriksaan.

Tabel 2. Fungsi masing-masing sekuens

\begin{tabular}{|c|c|}
\hline Sekuens & Fungsi \\
\hline T1_W & $\begin{array}{l}\text { Untuk melihat ada atau } \\
\text { tidaknya kelainan } \\
\text { anatomi pada pelvis }\end{array}$ \\
\hline T2_W & $\begin{array}{l}\text { Untuk melihat kelainan yang } \\
\text { dicurigai kista atau bukan }\end{array}$ \\
\hline $\begin{array}{l}\text { T1 Fat } \\
\text { supression }\end{array}$ & $\begin{array}{l}\text { Untuk melhat kelainan yang } \\
\text { dicurigai intensitasnya darah atau } \\
\text { bukan }\end{array}$ \\
\hline $\begin{array}{l}\text { T2 Fat } \\
\text { supression }\end{array}$ & $\begin{array}{l}\text { Untuk kelainan seperti kista } \\
\text { dengan menggunakan T2 dengan } \\
\text { teknik fat supression akan } \\
\text { kelihatan lebih jelas }\end{array}$ \\
\hline T2 3 planar & $\begin{array}{lrr}\text { Untuk mencari } & \text { adanya } & \text { fibrosis } \\
\text { atau modul } & \text { padat } & \text { yang } \\
\text { menginfiltrasi } & \text { organ } & \text { organ } \\
\text { disekitar rongga pelvis } & \end{array}$ \\
\hline DWI_Ssh & $\begin{array}{l}\text { Untuk melihat adanya curiga } \\
\text { kelainan lain seperti tumor atau } \\
\text { kanker }\end{array}$ \\
\hline
\end{tabular}

\section{Teknik pemeriksaan}

a. Pasien datang ke unit radiologi dengan membawa surat permintaan dari dokter pengirim, selanjutnya pasien diminta untuk mengganti pakaian dengan baju pemeriksaan. Setelah ganti baju kemudian lakukan screening dan informed consent.

b. Pasien di instruksikan masuk ke ruang MRI, selanjutnya posisikan pasien dengan posisi litotomi. Kemudian instruksikan kepada perawat radiologi untuk memasukkan $50 \mathrm{cc}$ ultrasonic gel dengan catheter tip ke vagina kemudian di mikropor. Selanjutnya pasien diminta untuk tidur miring kemudian masukkan $150 \mathrm{cc}$ ultrasonic gel dengan catheter tip ke anus lalu di mikropor agar gelnya tidak keluar. Setelah selesai di masukkan gel selanjutnya pasien disuruh supine, atur koil kemudian minta perawat untuk memasukkan buskopan melalui intravena setelah itu baru di positioning. c. Pasien diatur tidur terlentang (supine) . Kaki dekat gantry (feet first), posisi pasien diatur sehingga Mid Sagital Plane (MSP) tepat dan sejajar dengan lampu indikator longitudinal. Tangan diatas kepala supaya tidak menganggu obyek yang akan diperiksa atau timbulnya artefak.

d. Body coil dipasang di atas perut pasien. Perhatikan posisi body coil terhadap pasien, body coil diatur dengan central point dipertengahan pelvis.

e. Fixing belt dipasang, tetapi diikat longgar agar pasien merasa nyaman, tetapi koil tidak mudak bergeser.

f. Headset dipasang ditelinga dengan musik, untuk mengurangi suara alat yang keras dan untuk membuat pasien lebih rileks.

g. Emergency buzzer diberikan untuk dipegang pasien, yang bisa ditekan tombolnya jika pasien merasa tidak nyaman saat pemeriksaan berlangsung.

h. Pasang selimut pasien agar pasien merasa lebih nyaman dan tidak kedinginan.

i. Registrasi pasien (input data pasien di komputer konsul).

j. Klik exam untuk memulai pemeriksaan.

k. Pilihan sekuens yang digunakan dapat dilihat pada tabel 2.

Setelah selesai pemeriksaan pasien dianjurkan ke toilet untuk mengeluarkan gel dengan cara membuka mikropor lalu jongkok seperti pipis biasa, karena dengan panas suhu tubuh gel akan mencair dengan sendiri. Selanjutnya cetak film dengan menggunakan printer Dryview 6850 Laser Imager kemudian dicetak pada film dengan ukuran besar yaitu $43 X 35 \mathrm{~cm}$ pada film dengan merk Fuji, pada saat proses filming dilakukan pengaturan windowing, caliper, insert plane, dan magnifikasi sehingga gambar terlihat jelas dan center.

\section{Alasan penggunaan ultrasonic gel pada pemeriksaan MRI Pelvis pada Kasus Endometriosis di Instalasi Radiologi Mayapada Hospital Jakarta Selatan}

Endometriosis merupakan kelainan yaitu menebalnya dinding endometrium bukan pada tempatnya. Karena endometriosis adalah penebalan dinding endometrium tapi bukan pada tempatnya lebih tepatnya ke organ lain maka perlunya peranan ultrasonic gel pada pemeriksaan pelvis pada kasus endometrios sebagai pembeda antara rongga vagina, rongga rectum dan kelainan. Lebih tepatnya untuk melihat batas-batas organ, antara jaringan normal dan jaringan patologis. 
Selain itu alasan lain penggunaan ultrasonic gel pada pemeriksaan MRI Pelvis pada kasus endometriosis, seandainya vagina dan rectum itu colaps, peranan gel itu sendiri adalah untuk memperlebar vagina dan rectum jadi mempermudah mengevaluasi deep infiltrating endometriosis (DIE). Efek samping dari ultrasonic gel bagi pasien juga tidak ada, asalkan gel dalam keadaan bersih. Cuma kekurangannya ketidaknyamanan pasien.

Alasan penggunaan ultrasonic gel pada pemeriksaan MRI Pelvis di Instalasi Radiologi Mayapada Hospital Jakarta adalah untuk menegakkan diagnosa pada Kasus Endometriosis terutama deep infiltrating endometriosis (DIE). Penggunaan ultrasonic gel sangat membantu dokter menegakkan diagnosa pada kasus endometriosis karena endometriosis adalah penebalan didnding endometrium tapi bukan pada tempatnya, yang paling umum itu di myometrium, perimetrium, tuba fallopi, ovari, dan vagina, yang lebih parahnya bisa di organ diluar pelvis contohnya ada sedikit kasus yang sampai ke mata, tapi jarang sekali terjadi, jadi dengan adanya penggunaan ultrasonic gel hasil gambaran MRI pada kasus endometriosis lebih jelas perbedaannya antara jaringan normal dengan jaringan patologis, contohnya antara rongga pelvis, rongga rectum dan kelainan. Selain itu penggunaan ultrasonic gel juga memperlihatkan batas-batas antar organ contohnya rahim ke rectum, batas antara kandung kencing sama rahim, jadi walaupun endomteriosis yang paling kecilpun akan kelihatan, Seperti gambar di bawah ini :

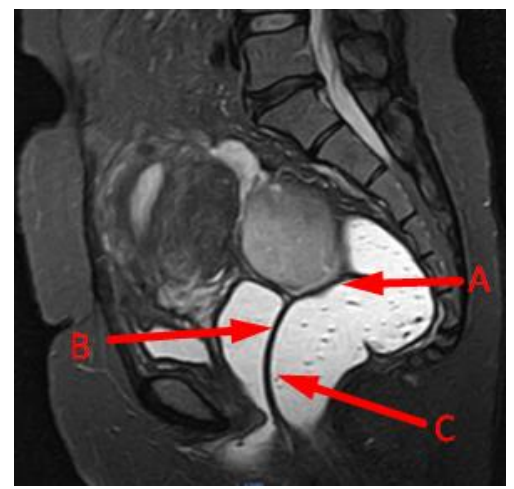

Gambar 1. Hasil gambaran MRI Pelvis dengan menggunakan ultrasonic gel

Keterangan

a. Terlihat jelas batas antara rectum dengan dinding rahim

b. Terlihat jelas batas antara vagina dengan dinding rahim

c. Terlihat jelas batas antara vagina dengan rectum

Selanjutnya penggunaan ultrasonic gel pada pemeriksaan MRI pelvis juga berperan untuk memperlebar rongga vagina dan rectum, jika vagina dan rectum kolaps jadi lebih mudah mengevaluasi endometriosis. Sedangkan menurut teori (Moeller, 2003) untuk Pemeriksaan MRI Pelvis pada Kasus Endometriosis tidak menggunakan Ultrasonic gel tapi dengan pemeriksaan MRI Pelvis biasa.

Menurut pendapat penulis penggunaan Ultrasonic Gel pada Pemeriksaan MRI pelvis pada Kasus Endometriosis di Mayapada hospital Jakarta Selatan sangat membantu dalam menegakkan diagnosa endoemteriosis, karena hasil gambaran yang optimal tetapi untuk hasil yang optimal tentu ada kekurangannya yaitu pada waktu pemeriksaanya (scan time) jadi lama dan ketidaknyamanan pada pasien karena adanya gel dalam vagina dan rectum.

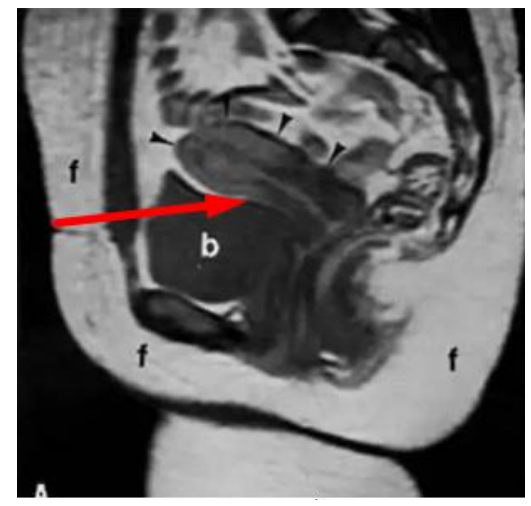

Gambar 2. Hasil gambaran MRI Pelvis tanpa menggunakan ultrasonic gel

Keterangan :

Tanda panah menunjukkan antara vagina, rectum dan dinding rahim kurang jelas batas-batas organnya, dan juga terlihat vagina dan rectum tidak mengembang dengan sempurna.

\section{Alasan penambahan sekuens T1_SPIR potongan sagital pada Kasus Endometriosis di Instalasi Radiologi Mayapada Hospital Jakarta Selatan.}

Alasan penambahan sekuns T1_SPIR potongan sagital adalah untuk melihat lesi yang dicurigai intensitasnya darah atau bukan. Karena endometriosis isinya adalah darah maka perlunya penambahan sekuens T1_SPIR potongan sagital. Dengan adanya T1_SPIR lesi yang dicurigai komponennya darah akan tetap terlihat putih sedangkan di sekuens lainnya sulit untuk memperlihat perbedaan intensitas darah atau yang bukan pada endometriosis.

Alasan penambahan sekuns T1_SPIR potongan sagital pada Kasus Endometriosis di Instalasi Radiologi Mayapada Hospital Jakarta Selatan membantu dalam mengevaluasi hasil gambaran 
MRI pada kasus endometriosis karena endometriosis ciri khas didalamnya adalah komponen darah jadi sekuens T1_SPIR potongan sagital untuk memperlihat lesi yang dicurigai intensitasnya darah atau bukan. Menurut teori (Moeller,2003) untukMRI pelvis tidak menggunakan $\mathrm{T} 1$ potongan sagital dengan teknik fat supression.

Menurut penulis penambahan sekuens T1_SPIR pada potongan sagital sangat optimal dalam menegakkan diagnosa pada hasil gambaran MRI Pelvis pada kasus endometriosis karena menurut radiolog di Mayapada Hospital Jakarta Selatan untuk sekuens lain pada pemeriksaan MRI Pelvis sulit untuk memperlihat perbedaan intensitas darah atau bukan pada kelainan yang dicurigai. Hal ini ditunjukkan pada gambar di bawah ini :

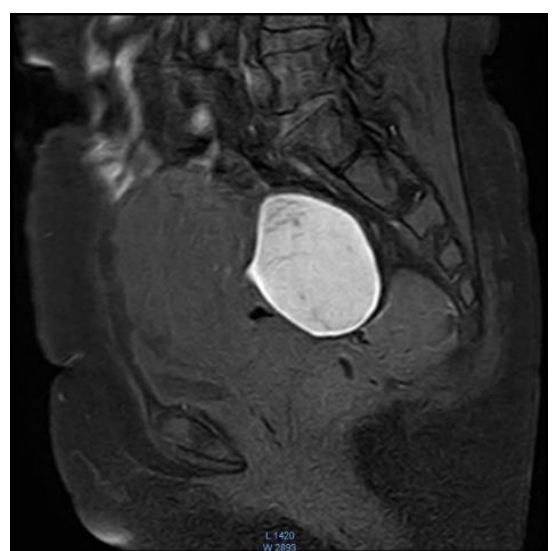

Gambar 3. Gambaran MRI sekuens T1_SPIR potongan Sagital Keterangan:

Tanda panah menunjukkan lesi yang dicurigai intensitasnya darah tetap berwarna putih artinya lesi yang intensitasnya darah tidak tersupresi pada sekuen T1_SPIR.

\section{Simpulan}

Prosedur pemeriksaan MRI Pelvis dengan menggunakan Ultrasonic Gel pada Kasus Endometriosis di Instalasi Radiologi Mayapada Hospital Jakarta Selatan tidak memerlukan persiapan khusus Cuma pasien disarankan tahan pipis sebelum pemeriksaan dan tidak menggunakan kontras apabila tidak dicurigai adanya kelainan lain. Untuk persiapan alat dan bahan untuk pemasukkan gel yaitu ultrasonic gel, catheher tip $50 \mathrm{cc}$, buscopan, spuit $5 \mathrm{cc}$, handscon dan mikropor. Adapun teknik pemeriksaannya adalah. posisi pasien litotomi. Kemudian instruksikan kepada perawat radiologi untuk memasukkan $50 \mathrm{cc}$ ultrasonic gel dengan catheter tip ke vagina kemudian di mikropor setelah itu posisikan pasien tidur miring kemudian masukkan
150 cc ultrasonic gel dengan catheter tip ke anus lalu di mikropor. Setelah selesai di masukkan gel selanjutnya pasien disuruh supine, atur koil kemudian instruksikan perawat untuk memasukkan buskopan melalui intravena. Parameter-parameter yang digunakan antara lain : T2W_TSE, T2W_SPIR, T1_SPIR, T1W, T2_FFE pada potongan sagital, T2W_TSE, T2W_SPAIR, T1W_SPIR pada potongan coronal, T1W_TSE, T1W_TSE_SPIR, T2W_TSE pada potongan axial serta DWI_3b_RT SENSE pada potongan axial dan SSh_URETER.

Alasan menggunakan ultrasonic gel pada pemeriksaan MRI Pelvis di Instalasi Radiologi Mayapada Hospital Jakarta adalah untuk memperlihatkan hasil gambaran MRI dengan memperlihatkan perbedaan yang jelas antara jaringan normal dengan jaringan patologis dan memperlihatkan dengan tegas batas-batas organ serta penggunaan ultrasonic gel pada pemeriksaan MRI pelvis juga berperan untuk memperlebar rongga vagina dan rectum, jika vagina dan rectum kolaps jadi lebih mudah mengevaluasi endometriosis.

Alasan penambahan sekuns T1_SPIR potongan sagital pada kasus Endometriosis di Instalasi Radiologi Mayapada Hospital Jakarta Selatan adalah untuk memperlihat lesi yang dicurigai intensitasnya darah atau bukan.

\section{Daftar Pustaka}

Gupta, Sajal et al. Endometriosis A Comprehensive Update. Newyork:Springer. 2015.

Oliver and Siegelman. MR Imaging of Endometriosis:ten Imaging Pearls. Philadelphia:RSNA. Volume:32 number:6. 2012

Paulsen, F dan J.Waschke. Sobotta atlas Anatomi Manusia. Jakarta:Kedokteran EGC. Edisi 23. 2013.

Ribeiro, M Margarid et al. STIR,SPIR and SPAIR Techniques in Magnetic Resonance of the breast. Portugal:J Biomedical Science and Engineering. 2013.

Sumiati. Sistem Reproduksi Manusia. Mataram:Jurnal Biologi. Volume 2 nomor 2. 2013.

Suparman, erna. Penatalaksaan Endometriosis. Manado:Jurnal Biomedik. Volume 4 nomor 2. 2012.

Suprijanto et al. Segmentasi Citra Secara SemiOtomatis Untuk Visualisasi Volumetrik Citra CT-Scan Pelvis. Bandung:makara Teknologi. Volume 13 nomor 2. 2009.

“Ultrasonic Couplant Gel”. Company Registration Number 6976251.

Westbrook, Chaterine, Carolyne Kaut and John Talbot. MRI in Practice Fourth Edition. United Kingdom: Blackwell Publishing Ltd. 2011. 
Westbrook, Chaterine. Handbook of MRI Technique Fourth Edition. United Kingdom:Wiley Blackwell Ltd. 2014. 